\title{
The food multimix concept: new innovative approach to meeting nutritional challenges in Sub-Saharan Africa
}

\author{
F. B. Zotor* and P. Amuna \\ Department of Life Sciences, University of Greenwich, School of Science, Chatham Maritime, Kent ME4 4TB, UK
}

\begin{abstract}
Food insecurity, chronic hunger, starvation and malnutrition continue to affect millions of individuals throughout the developing world, especially Sub-Saharan Africa. Various initiatives by African governments and International Agencies such as the UN, the industrial nations, the International Monetary Fund, the World Bank and the World Trade Organisation to boost economic development, have failed to provide the much-needed solution to these challenges. The impact of these economic shifts and the failures of structural adjustment programmes on the nutritional well-being and health of the most vulnerable members of poor communities cannot be over-emphasised. The use of ad hoc measures as an adjunct to community-based rural integrated projects have provided little success and will be unsustainable unless they are linked to harnessing available local resources. The present paper therefore focuses on exploring alternative ways of harnessing the scant agricultural resources by employing a scientific approach to food-related problem-solving. The food multimix (FMM) concept offers a scientific contribution alongside other attempts currently in use by the World Food Programme, WHO and FAO to meet the food insecurity challenges that confront most of the developing world in the twenty-first century. It is an innovative approach that makes better use of traditional food sources as a tool for meeting community nutritional needs. The FMM concept employs a food-based approach using traditional methods of food preparation and locallyavailable, cheap and affordable staples (fruits, pulses, vegetables and legumes) in the formulation of nutrient-enriched multimixes. Developed recipes can provide $\geq 40 \%$ of the daily nutritional requirements of vulnerable groups, including patients with HIV/AIDS and children undergoing nutrition rehabilitation. The FMM approach can also be used as a medium- to longterm adjunct to community-based rural integration projects aimed at health improvement and economic empowerment in Sub-Saharan Africa.
\end{abstract}

\section{Food multimix concept: Food insecurity: Nutrient enrichment: Sub-Saharan Africa}

Historically, it is well known that the application of fundamental concepts and principles remains the engine for technological development and technology transfer. For instance, applications of the fundamentals of chemistry, physics, electronics and engineering have formed the basis for developments in laser technology, nuclear energy, computer technology, mobile telephones, ipods and the internet. These developments have revolutionised human economic activity and output, widened access to knowledge transfer and improved efficiency globally. Similarly, agricultural and food technology and improved storage processes have improved shelf-lives and made food more widely available to consumers.

Africa is well endowed with vast agricultural, material and human resources and economic potential that continues to be under-utilised, and Africans remain among the poorest populations in the world, with nine of the ten poorest countries located in Sub-Saharan Africa ${ }^{(1)}$. Food insecurity remains the greatest challenge, and ad hoc measures have often been employed to address chronic hunger and household food insecurity, particularly in poor countries unable to deal with early warning signs of famine and starvation. Most often such countries have little or no national grain reserves, nor do they have properly functioning agricultural systems and efficient markets to support agricultural outputs during an abundant harvest. Furthermore, the application of food technology guided by a knowledge of nutrition and human health has so far had very limited application within the African context; therefore, even in times of plenty, effective biological

\footnotetext{
Abbreviations: FMM, food multimix; INQ, relative index of nutritional quality; RNI, reference nutrient intake. *Corresponding author: Dr F. B. Zotor, fax +44 208331 9805, email F.B.Zotor@gre.ac.uk
} 


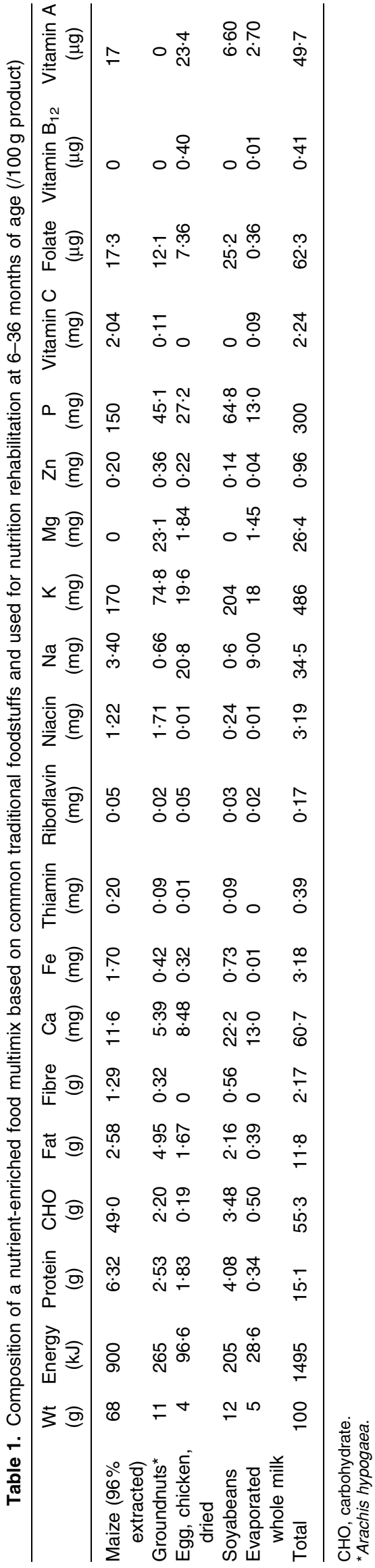

utilisation of food sources for health benefits remains unfulfilled.

Food security is defined as the situation in which all individuals and communities at all times have physical, social and economic access to sufficient, safe and nutritious food that meets their energy and nutrient requirements for an active and healthy life ${ }^{(2)}$, and it remains elusive for many millions of individuals in developing countries. Ad hoc food-intervention measures are often limited in scope, coverage and overall medium- to longterm impact. Also, they do not address underlying causes of food insecurity and do not in themselves offer solutions to the perennial problems. Furthermore, the majority of food interventions focus on food energy, with an average ration providing approximately $5.02 \mathrm{MJ} / \mathrm{d}$, a shortfall of $\geq 2.92 \mathrm{MJ} / \mathrm{d}$ for an average adult ${ }^{(3)}$.

Food aid rations are often imported grains, cereals and legumes and do not necessarily take into account local traditional and commonly-consumed food ingredients and/ or local alternatives. More importantly, rations that mainly comprise cereals and grains and oils, although energy dense, do not provide a good balance of the minerals and vitamins (micronutrients) essential to drive the energygiving metabolic processes that promote human growth, development and reproductive potential. The natural coping strategy in extreme conditions of limited food availability and chronic hunger is for the organism to 'economise' their energy use through hormonal and other metabolic adaptations. Although these adaptations are seemingly protective in the short term, they may lead to 'thrifty phenotypes and genotypes' ${ }^{(4,5)}$ that increase the individual's susceptibility to malnutrition and infectious disease $^{(6)}$ during periods of prolonged hunger and poverty, and non-communicable diseases, including type 2 diabetes and $\mathrm{CVD}^{(7,8)}$, during periods of affluence and/or nutritional adequacy. It is therefore not unexpected that developing countries carry a much higher burden of morbidity and mortality from non-communicable diseases (approximately $78 \%$ ) than food self-sufficient industrialised countries (approximately 58\%).

The food multimix $(\mathrm{FMM})$ concept $^{(9-11)}$ essentially states that irrespective of environment it is possible through the application of knowledge of food science and technology, nutrition, human biochemistry and metabolism in health and disease (and within a social and cultural context) to make effective use of locally-available and commonly-consumed but scant food resources to meet human needs across the age-ranges. An FMM is therefore a food product based on recipes developed through the effective combination of individual locallyavailable and commonly-consumed food ingredients (or candidate foods), making use of their 'nutrient strengths'. Blended together, the ingredients serve as 'natural fortificants', thus providing a nutrient-enriched end product at relatively low cost without the need for external fortification (for an example, see Table 1). Such blends or mixes can be produced within a cultural context and utilise local food processing technology to help maintain their sensory characteristics and encourage their acceptability among the target population or client groups. 
The FMM concept is a growing concept that is gaining wider recognition and acceptance amongst fellow scientists as a simple sensible approach to the application of scientific knowledge in the harnessing of nutrient sources to meet human needs under sometimes difficult circumstances. In trying to transfer and diffuse this knowledge and its potential applications more widely, project partnerships have been developed with colleagues in a number of African countries including Ghana and South Africa to support nutrition intervention projects in those countries utilising their own local and natural food sources.

This concept has many applications and has been used to develop food products for clinical and non-clinical population groups (i.e. weanlings, infants, pregnant women, individuals infected with HIV/AIDS and individuals with type 2 diabetes). The implications of poor food intake for growth and development across the life cycle are enormous. Poor nutritional status adds extra pressures during the key stages of development such as in fetal growth and the infantile growth spurt and in altered physiological states such as pregnancy. In pregnancy recognition of these nutritional stresses ${ }^{(12,13)}$ and their immediate and longerterm impact has led to the hypothesis of 'nutritional programming'. The immediate direct impact of nutrient deficiency on pregnancy outcomes, however, is very well established in relation to cretinism ${ }^{(14,15)}$ and neural-tube defects $^{(16)}$. Furthermore, there is accumulating evidence to indicate that chronic maternal $\mathrm{Fe}$ deficiency is related to low birth weight and other neonatal and infant morbidities $^{(17)}$. Similarly, maternal vitamin A status has been shown to be correlated with a risk of vertical transmission of infections, including HIV infection ${ }^{(18,19)}$.

The importance of good nutritional support in the clinical management of disease is also increasingly being recognised, particularly in industrialised countries ${ }^{(20,21)}$ in which regular clinical audits are being undertaken to support evidence-based medical practice and interventions. Nutritional status is a recognised prognostic index for diseases such as HIV/AIDS, which has a high prevalence in Sub-Saharan Africa. Regrettably, there are currently neither coherent nor structured nutrition policy guidelines for supporting hospitalised patients in general and those suffering from HIV/AIDS in particular in most SubSaharan African countries.

The urgent need for appropriate nutritional support is quite clear. The present paper demonstrates the processes through which this support may be achieved in contributing towards short-term clinical needs. It may further be applied to meeting the nutritional needs of special (vulnerable) groups in food-insecure communities, as part of integrated food-related interventions aimed at promoting good health and supporting primary prevention strategies.

\section{Objectives}

The primary objective of the project was to design FMM to meet the nutrient requirements of specific target groups, taking into account clinical need, metabolic considerations and factors influencing nutrient bioavailability. A further objective was to establish the dietetic, clinical and field
Table 2. Composition of a typical food multimix and its cost per $300 \mathrm{~g}$ serving of the product based on prices in a local African market

\begin{tabular}{lcc}
\hline Food item & $\begin{array}{c}\text { Weight } \\
(\mathrm{g})\end{array}$ & $\begin{array}{c}\text { Cost }^{\star} \\
\left.\text { (pence }^{*} \mathbf{3 0 0} \mathrm{g}\right)\end{array}$ \\
\hline Millet & 135 & 1.9 \\
Cowpea (Vigna & 75 & $2 \cdot 2$ \\
$\quad$ unguiculata) & & \\
Melon seeds & 30 & $1 \cdot 6$ \\
Dry fish & 45 & 1.2 \\
Palm oil & 15 & 0.6 \\
Total & 300 & 7.5
\end{tabular}

*The prices of items obtained from local market sources in Ghana in April 2004, when the exchange rate was 18776 cedis/£1 and the minimum wage was 11500 cedis/d.

applications of FMM products within a cultural context through sensory evaluation and acceptability assessments. Finally, the project focused on developing cost-effective dietetic products (Table 2) to meet at least $40 \%$ of daily requirements per serving, drawing from energy and nutrient strengths of individual components in the form of local foodstuffs without the need for fortification.

\section{Study design}

Materials and methods

Standard food composition tables and nutrition databases $^{(22-25)}$ were used to estimate nutrient content and 'nutrient strengths' of local food ingredients. The food ingredients were purchased in London, UK from a local African stall and included cereals, legumes, pulses and nuts and fruits. The FMM were formulated on the basis of the physiological and/or clinical needs of the target groups: weanlings aged 6-9 months; children aged 6-36 months at various stages of nutrition rehabilitation (lower-strength and higher-strength formulas). FMM were also developed for adults with HIV/AIDS and for pregnant women.

Proximate analyses of macronutrients were conducted to determine the following: protein content, by employing the Kjeldahl method with a modified Berthelot reaction ${ }^{(26)}$; lipid determination, by employing the AOAC International acid-hydrolysis standard official method $922 \cdot 06^{(27)}$. Dietary fibre was estimated using standard food composition databases and total carbohydrate (\%) analysis was calculated as: $100 \%-\%($ protein + fat + ash + moisture $)$, where $\%($ protein + fat + ash + moisture $)$ was obtained from the results of the proximate analyses.

FMM samples were digested in concentrated $\mathrm{HNO}_{3}$ (Aristar 68\%; BDH Laboratory Supplies, Poole, Dorset, $\mathrm{UK}$ ) and mineral contents ( $\mathrm{Ca}, \mathrm{Fe}, \mathrm{Cu}, \mathrm{Mg}, \mathrm{K}$ and $\mathrm{Zn}$ ) were determined using atomic absorption spectrometry and inductively-coupled plasma MS. Vitamin content (thiamin, riboflavin, niacin, folate, vitamins $\mathrm{B}_{12}, \mathrm{~A}$ and $\mathrm{C}$ ) was estimated from nutrient databases and subsequently correlated with experimental energy and nutrient values. Optimisation of FMM followed initial experimental analyses in order to enrich their nutritive values for the intended targets. 
Table 3. A comparison of the energy and nutrient contents of nutrient-enriched food multimixes for weanlings and children that are based on common traditional foodstuffs with those of Ghanaian products (per $100 \mathrm{~g}$ serving)

\begin{tabular}{|c|c|c|c|c|c|c|c|c|}
\hline & \multicolumn{2}{|c|}{$\begin{array}{l}\text { Weanlings } \\
\text { (6-9 months) }\end{array}$} & \multicolumn{2}{|c|}{$\begin{array}{c}\text { Nutrition } \\
\text { rehabilitation } \\
\text { (6-36 months): } \\
\text { lower strength }\end{array}$} & \multicolumn{2}{|c|}{$\begin{array}{l}\text { Nutrition } \\
\text { rehabilitation } \\
\text { (6-36 months): } \\
\text { higher strength }\end{array}$} & \multirow[b]{2}{*}{ Weanimix $\|$} & \multirow[b]{2}{*}{ Koko ${ }^{\mathbb{R}}$} \\
\hline & Mean & SE & Mean & SE & Mean & SE & & \\
\hline \multicolumn{9}{|l|}{ Proximate analysis } \\
\hline Energy density (kJ/g) & $15 \cdot 4$ & 0.51 & $14 \cdot 6$ & $0 \cdot 19$ & $16 \cdot 5$ & 0.32 & $18 \cdot 2$ & $16 \cdot 2$ \\
\hline \multicolumn{9}{|l|}{ Energy (\%) from: } \\
\hline Protein & $13 \cdot 8$ & 0.39 & $12 \cdot 0$ & $1 \cdot 85$ & $15 \cdot 2$ & 0.54 & $13 \cdot 8$ & $25 \cdot 8$ \\
\hline $\mathrm{CHO}$ & $49 \cdot 5$ & $0 \cdot 74$ & $58 \cdot 2$ & $1 \cdot 61$ & $56 \cdot 6$ & 0.29 & $62 \cdot 6$ & $66 \cdot 0$ \\
\hline Fat & $36 \cdot 8$ & $0 \cdot 61$ & $29 \cdot 8$ & 0.98 & $28 \cdot 2$ & 0.58 & $23 \cdot 6$ & $8 \cdot 14$ \\
\hline Percentage of $\mathrm{EAR}^{\star}$ per serving & $46 \cdot 3$ & & $36 \cdot 3$ & & $41 \cdot 0$ & & $45 \cdot 2$ & $40 \cdot 2$ \\
\hline \multicolumn{9}{|l|}{ Mineral content $\dagger$} \\
\hline Percentage of RNI & $55 \cdot 6$ & & $32 \cdot 1$ & & $58 \cdot 2$ & & $54 \cdot 8$ & $86 \cdot 4$ \\
\hline INQ & $1 \cdot 20$ & & $0 \cdot 88$ & & $1 \cdot 42$ & & $1 \cdot 21$ & $2 \cdot 15$ \\
\hline \multicolumn{9}{|l|}{ Vitamin content§ } \\
\hline Percentage of RNI & $96 \cdot 3$ & & $59 \cdot 9$ & & $77 \cdot 2$ & & $49 \cdot 1$ & 132 \\
\hline INQ & $2 \cdot 08$ & & $1 \cdot 65$ & & $1 \cdot 89$ & & $1 \cdot 09$ & $3 \cdot 29$ \\
\hline
\end{tabular}

EAR, estimated average requirement; RNI, reference nutrient intake; INQ, relative index of nutritional quality (nutrient:energy content ${ }^{(28)}$ ).

${ }^{*}$ Atwater factors were applied and values calculated as the average for males and females in each age-group.

†Mean content of seven vitamins (thiamin, riboflavin, niacin, folate and vitamins $\mathrm{B}_{12}, \mathrm{~A}$ and $\mathrm{C}$ )

$\ddagger$ As there are no published Ghanaian RNI values, RNI were adapted from UK values ${ }^{(3)}$.

$\S$ Mean content of four minerals ( $\mathrm{Ca}, \mathrm{Fe}, \mathrm{Zn}$ and $\mathrm{K})$.

|Introduced by the Ghanaian Ministry of Health Nutrition Division and UNICEF/Ghana in 1987 to improve food quality and contains (g/kg): 100-150 soyabeans or cowpeas (Vigna unguiculata); 100 peanuts (Arachis hypogaea); $750-800$ maize 29 ).

- ILocal fermented maize porridge with a low energy and nutrient density that has been fortified with fish meal ${ }^{(29)}$

FMM were then processed into porridge, soup, biscuits and cakes. Sensory evaluation was conducted in Ghana, West Africa to ascertain the acceptability of the various products.

\section{Subjects}

Subjects (n 1039) aged 11-15 years (school-age group) and 18-68 years (adult group), males and females, were recruited to take part in the sensory evaluation of FMM products and both parental and written consent was obtained. Subjects were selected using a procedure involving two-stage cluster sampling followed by stratified sampling. School-age children were recruited from a cluster of junior secondary schools in Accra and adult groups were recruited from the Korle-Bu teaching hospital in Accra and the Ministry of Education in Accra. Sensory evaluation tests took place between May and September 2003 following ethical approval from the Health Research Unit, Ghana Health Service. The volunteers were asked to indicate the extent of acceptability of products in terms of appearance, colour, smell, flavour and texture. Based on the assessment of these characteristics, an overall acceptability of the products consumed was ranked from 0 to 10 employing a Likert scale.

\section{Data analysis}

Data collected were analysed using Excel version 5.0. Results are presented as means with their standard errors to ascertain the level of variation of nutrient content in FMM formulated within each target group. Logistic regression analysis was used to predict the relationship between FMM edible-product characteristics and their acceptability among the different age-groups of consumers involved in the sensory evaluation test, from which the regression coefficient and OR were calculated. Values were considered significant at $P \leq 0 \cdot 05$.

\section{Results}

Energy densities (kJ/g product) of optimised FMM for weanlings, lower-strength nutrition rehabilitation and higher-strength nutrition rehabilitation were $15 \cdot 4$ (SE 0.51), $14 \cdot 6$ (SE 0.19), 16.5 (SE 0.32) respectively. FMM for patients with HIV/AIDS and pregnant women had energy densities (kJ/g product) of 16.4 (SE 0.17) and 16.4 (SE 0.25) respectively. The percentage energy from protein, carbohydrate and fat for each target group was respectively $13 \cdot 8$, $49 \cdot 4$ and $36 \cdot 8$ for infant weanlings, $12 \cdot 0,58 \cdot 2$ and $29 \cdot 8$ for lower-strength nutrition rehabilitation and 15.2, 56.6 and 28.2 for higher-strength nutrition rehabilitation, which provided a percentage contribution to daily energy requirements (estimated average requirements; Atwater factors were applied and values calculated as the average for males and females in each age-group) per serving (100 g) for these target groups of $46 \cdot 3,36 \cdot 3$ and $41 \cdot 0$ respectively (Table 3 ). The percentage energy from protein, carbohydrate and fat was respectively $24 \cdot 5,45 \cdot 2$ and $30 \cdot 4$ for patients with HIV/AIDS and 19.8, $47 \cdot 4$ and $32 \cdot 8$ for pregnant women. The percentage contribution to daily energy requirements (estimated average requirements) per serving $(300 \mathrm{~g})$ for these target groups was 52.4 and $55 \cdot 1$ 
Table 4. A comparison of the energy and nutrient contents of nutrient-enriched food multimixes for adults that are based on common traditional foodstuffs with those of WHO/FAO products (per $300 \mathrm{~g}$ serving)

\begin{tabular}{|c|c|c|c|c|c|c|}
\hline & \multicolumn{2}{|c|}{ HIV/AIDS } & \multicolumn{2}{|c|}{ Pregnancy } & \multicolumn{2}{|c|}{ WHO $\|$} \\
\hline & Mean & SE & Mean & SE & $A$ & $\mathrm{~B}$ \\
\hline \multicolumn{7}{|l|}{ Proximate analysis } \\
\hline Energy density (kJ/g) & $16 \cdot 4$ & $0 \cdot 17$ & $16 \cdot 4$ & 0.24 & $6 \cdot 11$ & $4 \cdot 62$ \\
\hline \multicolumn{7}{|l|}{ Energy (\%) from: } \\
\hline Protein & $24 \cdot 5$ & 0.25 & $19 \cdot 3$ & 0.93 & 13 & 13 \\
\hline $\mathrm{CHO}$ & $45 \cdot 2$ & 0.46 & $48 \cdot 0$ & 0.89 & 59 & 59 \\
\hline Fat & $30 \cdot 4$ & 0.65 & $32 \cdot 7$ & $0 \cdot 81$ & 28 & 28 \\
\hline Percentage of $\mathrm{EAR}^{\star}$ per serving & $52 \cdot 4$ & & $55 \cdot 1$ & & $44 \cdot 5$ & $44 \cdot 5$ \\
\hline \multicolumn{7}{|l|}{ Mineral content $\dagger$} \\
\hline Percentage of RNI & 138 & & 131 & & $46 \cdot 8$ & $51 \cdot 6$ \\
\hline INQ & $2 \cdot 63$ & & $2 \cdot 38$ & & $1 \cdot 05$ & $1 \cdot 16$ \\
\hline \multicolumn{7}{|l|}{ Vitamin content§ } \\
\hline Percentage of RNI¥ & 121 & & $89 \cdot 3$ & & 119 & 127 \\
\hline INQ & $2 \cdot 32$ & & 1.62 & & $2 \cdot 06$ & $2 \cdot 86$ \\
\hline
\end{tabular}

EAR, estimated average requirement; $\mathrm{RNI}$, reference nutrient intake; INQ, relative index of nutritional quality (nutrient:energy content ${ }^{(28)}$ )

*Atwater factors were applied and values calculated as the average for males and females.

†Mean content of seven vitamins for the food multimixes (thiamin, riboflavin, niacin, folate and vitamins $\mathrm{B}_{12}, \mathrm{~A}$ and $\mathrm{C}$ ) and of three vitamins for the WHO composite mixes (folate and vitamins $A$ and $C$ ).

$\ddagger$ As there are no published Ghanaian RNI values, RNI were adapted from UK values ${ }^{(3)}$

$\S$ Mean content of four minerals for the food multimixes (HIV/AIDS: Ca, Fe, Cu and Zn; pregnancy: Ca, Fe, Mg and K) and three minerals for WHO composite

mixes ( $\mathrm{Ca}$, Fe and $\mathrm{Zn})$.

$\| \mathrm{A}$ is a rice-based composite mix, $684 \mathrm{~g}$; $\mathrm{B}$ is a potato-based composite mix, $905 \mathrm{~g}^{(30)}$.

respectively (Table 4). The pooled mean contribution of an average of four different minerals to the daily requirements for all target groups (the percentage of the reference nutrient intake (RNI); as there are no published Ghanaian RNI values, RNI were adapted from UK values ${ }^{(3)}$ ) and the relative index of nutritional quality (nutrient:energy content; INQ ${ }^{(28)}$ )were calculated. For infant weanlings $55 \cdot 6 \%$ of the RNI was met, with a pooled mean INQ of $1 \cdot 20$. Slightly lower contributions were met for the two nutritional-rehabilitation groups (Table 3). Similarly, the percentage contributions to the RNI and the INQ for the FMM for the adult groups were respectively 137.5 and 2.63 for patients with HIV/AIDS and $130 \cdot 8$ and 2.38 for pregnant women (Table 4).

The pooled means for the vitamin content for an average of seven vitamins would provide $\geq 89 \%$ of the RNI and a mean INQ $>1.60$ for all target groups (Tables 2 and 3).

The products were overwhelmingly endorsed following sensory evaluation, with $>91 \%$ acceptability $(P=0 \cdot 005)$. However, age (OR 1.44 for 11-15-year-olds and 2.01 for 18-68-year-olds) and gender $(P=0 \cdot 000)$ were major influences on product preference.

Logistic regression analysis was employed to test the relationship between product sensory characteristics and acceptance. School-age (junior secondary schools) subjects were significantly influenced by the appearance of the product $(P>0 \cdot 001$, OR $5 \cdot 34)$. The influence of smell on acceptability indicated that among school-age children a fishy smell was acceptable $(P=0 \cdot 043$; OR $0 \cdot 22)$, but adult subjects had a greater preference for the fishy smell $(P=0 \cdot 009 ;$ OR $15 \cdot 46)$. Among all subjects the rating for palatability of the products was extremely high $(\mathrm{OR}=1.44$ and $2 \cdot 01$ for 11-15-year-olds and 18-68-year-olds respectively; $P=0 \cdot 000$ ), but where there was a bitter taste, the product was not acceptable $(P=0.020$; OR 0.66 for junior secondary schools). A hard texture $(P=0 \cdot 029$; OR $0 \cdot 25)$ was also deemed less acceptable by school-age children and was likely to lead to product rejection. A strongly sour taste was also more likely to lead to rejection among adults $(P=0 \cdot 003$; OR $0 \cdot 57)$. Other sensory characteristics did not significantly influence acceptability on the basis of the statistical analysis and so have not been included.

\section{Discussion}

The newly-formulated FMM compared favourably with existing commercially-available (and fortified) food products for children including Weanimix (introduced by the Ghanaian Ministry of Health Nutrition Division and UNICEF/Ghana in 1987 to improve food quality and contains (g/kg): 100-150 soyabeans or cowpeas (Vigna unguiculata); 100 peanuts (Arachis hypogaea); 750-800 maize) and protein-enriched Koko ${ }^{\mathbb{R}}$ (local fermented maize porridge with a low energy and nutrient density that has been fortified with fish meal) ${ }^{(29)}$ (Table 3). FMM formulated to meet nutrient requirements of adults under different conditions also compared favourably with two FAO/WHO products (a rice-based composite mix and a potato-based composite mix $^{(30)}$; Table 4$)$. Through the use of local traditional mostly plant-based food ingredients it has been demonstrated that the nutritive values of individual components of the diet can be effectively combined to improve nutritional quality and possibly benefit vulnerable groups without necessarily fortifying the products or supplementing them with synthetic products.

Most Fe sources were non-haem-Fe from plant sources. Absorption of $\mathrm{Fe}$ is negatively influenced by $\mathrm{Ca}$, phytates 
and fibre found in cereals and legumes ${ }^{(31,32)}$. The presence of $\mathrm{Cu}$ in $\mathrm{FMM}$, however, would enhance the Fe absorption and $\mathrm{Cu}$ also has antioxidant properties and influences $\beta$-cell function $^{(33,34)}$. The daily inclusion of citrus fruits (and/or fruit juices where affordable) containing ascorbic acid would increase the non-haem-Fe absorption by at least two- to threefold ${ }^{(35,36)}$.

FMM contain sufficient $\mathrm{Fe}$ to meet daily requirements despite the presence of inhibitory factors. Risk of $\mathrm{Fe}$ overload has previously been reported by other workers in relation to African diets ${ }^{(37,38)}$, but the evidence is rather weak and inconsistent. Moreover, with the exception of therapeutic feeding in the acute phase of protein-energy malnutrition and HIV, in which case care was taken to limit the Fe content of the FMM, generally these FMM are targeted at populations who may require $\mathrm{Fe}$ repletion and it is expected that if there is any risk of $\mathrm{Fe}$ overload it will be minimal.

There is no doubt that dietary supplements and fortified foods have their place in clinical management, but their overall efficacy, because of costs and the ability of poor communities to sustain fortification and supplementation programmes, remains highly debatable. The identification of suitable vehicles for fortification remains a challenge and the assurance that local consumers would use such vehicles has not been fully evaluated. There are advantages in utilising commonly-accessible affordable identifiable food sources and processing methods that are familiar and culturally appropriate to poor communities. There is also evidence that natural food sources of nutrients are better absorbed than expensive synthetic supplements ${ }^{(39,40)}$.

These results demonstrate that it is possible in one composite mix to provide a food product that meets minimum nutrient requirements by employing this food-based approach, even in poor communities. The findings support the hypothesis that energy and micronutrient needs of individuals and population groups in poor communities can be met through scientific approaches to dietary manipulation employing traditional food ingredients without the need for fortification. This approach is much more cost-effective than a single-nutrient approach.

\section{References}

1. World Bank (2003) World Development Report 2003: Sustainable Development in a Dynamic World: Transforming Institutions, Growth, and Quality of Life. New York: World Bank and Oxford University Press.

2. Food and Agriculture Organization (1996) Rome Declaration on World Food Security and World Food Summit Plan of Action. http://www.fao.org/docrep/003/w3613e/w3613e00. htm

3. Department of Health (1991) Dietary Reference Values for Food Energy and Nutrients for the UK. Report on Health and Social Subjects no. 41. London: H. M. Stationery Office.

4. Barker D (1992) Fetal and Infant Origins of Adult Disease. London: BMJ Books.

5. Kuzawa CW (2005) Fetal origins of developmental plasticity: are fetal cues reliable predictors of future nutritional environment? Am J Hum Biol 17, 5-21.
6. Prentice AM \& Goldberg GR (2000) Energy adaptations in human pregnancy: limits and long-term consequences. Am J Clin Nutr 71, Suppl., 1226S-1232S.

7. Barker DJ (2000) In utero programming of cardiovascular disease. Theriogenology 53, 555-574.

8. Wells JCK (2003) The thrifty phenotype hypothesis: thrifty offspring or thrifty mother? J Theor Biol 221, 143-161.

9. Amuna P, Zotor F, Chinyanga YT \& Chinyanga YT (2000) The role of traditional cereal/legume/fruit-based multimixes in weaning in developing countries. Nutr Food Sci 30, 116122.

10. Amuna P, Zotor F \& Tewfik I (2004) Human and economic development in developing countries: a public health dimension employing the food multimix concept. World Rev Sci Technol Sustain Dev 1, 129-137.

11. Zotor FB (2006) A novel approach to the development of nutrient-enriched traditional food multimixes for clinical and population-based nutrition interventions. $\mathrm{PhD}$ Thesis, University of Greenwich.

12. Hobel C \& Culhane J (2003) Role of psychosocial and nutritional stress on poor pregnancy outcome. J Nutr 133, 1709S-1717S.

13. Jackson AA, Bhutta ZA \& Lumbiganon P (2003) Introducing nutrition as a preventive strategy against adverse pregnancy outcomes. J Nutr 133, 1589S-1591S.

14. Saavedra JM, Henderson RA \& Perman JA (1995) Longitudinal assessment of growth in children born to mothers with human immunodeficiency virus infection. Arch Pediatr Adolesc Med 149, 497.

15. Semba RD, Miotti P, Chiphangwi JD, Henderson R, Dallabetta G, Yang LP \& Hoover D (1997) Maternal vitamin A deficiency and child growth failure during human immunodeficiency virus infection. J Acquir Immune Defic Syndr Hum Retrovirol 14, 219-222.

16. Barker DJP (1995) Foetal origins of coronary heart disease. Br Med J 311, 171-174.

17. Cook JD, Dassenko D \& Whittaker P (1991) Calcium supplementation: effect on iron absorption. Am J Clin Nutr 53, 106-111.

18. Edge R, McGarvey DJ \& Truscott TG (1997) The carotenoids as anti-oxidants - a review. J Photochem Photobiol $B$ 41, 189-200.

19. Cui D, Moldoveanu Z \& Stephenson CB (2000) High level dietary vitamin $\mathrm{A}$ enhances $\mathrm{T}$ helper type 2 cytokine production and secretory immunoglobulin A response to influenza A virus infection in mice. $J$ Nutr 30, 1132-1139.

20. McKinley J \& Marceau L (2000) US public health and the 21 st century diabetes mellitus. Lancet 356, 757-761.

21. World Health Organization (2002) Diabetes: The Cost of Diabetes. Fact Sheet no. 236. Geneva: WHO.

22. Eyeson KK \& Ankrah EK (1975) Composition of Foods Commonly Used in Ghana. Accra, Ghana: Food Research Institute (CSIR), UNDP and FAO.

23. Westbrink S, Knuiman JT, West CE, van der Heijden L \& van de Bovenkamp P (1983) Nutrient Composition of 167 Food Items from Ghana, The Philippines, Italy and Finland. Food Analyses of the Department of Human Nutrition (Netherlands), vol. III. Wageningen, The Netherlands: Wageningen Agricultural University, Department of Human Nutrition.

24. West CE, Pepping F \& Temalilawa CR (1988) The Composition of Foods Commonly Eaten in East Africa. Wageningen, The Netherlands: Wageningen Agricultural University.

25. Langenhoven ML, Kruger M, Gouws E \& Faber M (1991) MRC Food Quantities Manual, 2nd ed. Parow, South Africa: South African Medical Research Council. 
26. Mason CJ, Coe G, Edwards M \& Riby P (1999) The use of microwaves in the acceleration of digestion and colour development in the determination of total Kjeldahl nitrogen in soil. Analyst 124, 1719-1726.

27. AOAC International (2000) Official Methods of Analysis of AOAC International, 17th ed., vol. 1 [A Horwitz, editor]. Gaithersburg, MD: AOAC International.

28. Lee RD \& Neiman DC (2003) Nutritional Assessment. Boston, MA: WCB McGraw-Hill.

29. Lartey A, Manu A, Brown KH, Peerson JM \& Dewey KG (1999) A randomised, community-based trial of the effects of improved, centrally processed complementary foods on growth and micronutrient status of Ghanaian infants from 6-12 mo of age. Am J Clin Nutr 70, 391-404.

30. Food and Agriculture Organization/World Health Organization (2001) Human Vitamin and Mineral Requirements. Report of a Joint FAO/WHO Expert Consultation. Rome: FAO.

31. Mamiro PRS, Van J, Mwikya A et al. (2001) In vitro extractability of calcium, iron, and zinc in finger millet and kidney beans during processing. J Food Sci 66, 1271-1275.

32. Hemalatha S, Platel K \& Srinivaska K (2007) Zinc and iron contents and their bioaccessibility in cereals and pulses consumed in India. Food Chem 2, 1328-1336.
33. Faure $P$ (2003) Protective effects of antioxidant micronutrients. Clin Chem Lab Med 41, 995-998.

34. Tapeiro H, Townsend DM \& Tew KD (2003) Trace elements in human physiology and pathology. Copper. Biomed Pharmacother 57, 386-398.

35. Lynch SR (1997) Interaction of iron with other nutrients. Nutr Rev 55, 102-110.

36. Allen JR \& Baur LA (2000). Iron deficiency in infants and young children. Med Today 1, 1-7.

37. Gangaidzo IT, Moyo VM, Saungweme T et al. (1999) Iron overload in urban Africans in the late 1990s. Gut 45, 278-283.

38. Kasvosve I, Delanghe JR, Gomo ZA et al. (2002) Effect of transferrin polymorphism on the metabolism of vitamin $\mathrm{C}$ in Zimbabwean adults. Am J Clin Nutr 75, 321-325.

39. Nielsen, FH (1994) Chromium. In Modern Nutrition in Health and Disease, 8th ed., pp. 264-268 [ME Shils, JA Olson and M Shike, editors]. Philadelphia, PA: Lea \& Febiger.

40. Vinson J, Bose P, Lemoine L \& Hsiao KH (1989) Bioavailability studies. In Nutrient Availability: Chemical and Biological Aspects, pp. 125-127 [DAT Southgate, IT Johnson and GR Fenwick, editors]. Cambridge: Royal Society of Chemistry. 